Jurnal Akuntansi \& Perpajakan, Volume 1, No. 2, Januari 2020

\title{
ANALYSIS OF THE MARKET LEADERSHIP ORIENTATION, INNOVATION STRATEGY AND BUSINESS PERFORMANCE
}

\author{
Setiarini ${ }^{1}$, Sri Irviati Wahyoeni ${ }^{2}$, Iha Haryani Hatta ${ }^{3}$, Widarto Rachbini ${ }^{4}$ \\ ${ }^{123}$ Economics and Bisnis Faculty, University of Pancasila \\ ${ }^{4}$ Postgraduate, University of Pancasila
}

\begin{abstract}
:
The Small Medium Enterprise (SME) Indonesia is able to absorb the largest of labor, therefore needs to support continuation through the achievement of optimal business performance. The Purpose of Research Analysis Market Orientation Leadership, Innovation Strategy and Business Performance (Study case SME in Jakata) has analysis the variable influence among of Market Orientation Leadership, Innovation Strategy and Business Performance. The population of this research are home industry SME in Jakarta, Data collection through surveys with respondents reelected as many as 162 purposive perpetrators of SME. The respondent's data has analyzed in Structural Equation Modeling (SEM), Lisrel's program. The results of the study as follows: The market orientation leadership influence to Innovation Strategy. The Variables of market orientation leadership and innovation strategy influence partial to business performance. The Innovation Strategy as the intervening as variables on the orientation market leadership and business performance variables.
\end{abstract}

Keywords : Market Leadership Orientation, Innovation Strategy, Business Performance

\section{ANALISIS ORIENTASI KEPEMIMPINAN PASAR, STRATEGI INOVASI DAN KINERJA USAHA}

\author{
Setiarini ${ }^{1}$, Sri Irviati Wahyoeni ${ }^{2}$, Iha Haryani Hatta ${ }^{3}$, Widarto Rachbini ${ }^{4}$ \\ ${ }^{123}$ Fakultas Ekonomi dan Bisnis Universitas Pancasila \\ ${ }^{4}$ Sekolah Pasca Sarjana Universitas Pancasila
}

\begin{abstract}
:
Peranan UMKM di Indonesia antara lain dapat menyerap tenaga kerja terbesar, karena itu UMKM perlu didukung keberlanjutannya melalui pencapaian kinerja usaha yang optimal. Penelitian tentang analisis orientasi kepemimpinan pasar, strategi inovasi, dan kinerja usaha (studi kasus UMKM di Jakarta) dengan tujuan ingin menganalisis pengaruh antar variabel orientasi kepemimpinan pasar, strategi inovasi, dan kinerja usaha. Populasi penelitian ini adalah UMKM home industry di Jakarta. Pengumpulan data melalui survey dengan responden terpilih secara purposive sebanyak 162 pelaku UMKM tersebut. Data dari responden tersebut dianalisis secara SEM, program Lisrel. Hasil penelitian sebagai berikut: orientasi kepemimpinan pasar berpengaruh terhadap inovasi. Variabel orientasi kepemimpinan pasar, dan strategi inovasi berpengaruh secara parsial terhadap kinerja usaha. Strategi inovasi berperan sebagai variabel yang mendukung pengaruh variabel orientasi kepemimpinan pasar terhadap kinerja usaha.
\end{abstract}

Kata-kata kunci : Orientasi Pemimpin Pasar, Strategi Inovasi, dan Kinerja Usaha.

Korespondensi : Setiarini, SE, M.Si. Fakultas Ekonomi dan Bisnis Universitas Pancasila. Jl. Srengseng Sawah, Jagakarsa, Jakarta Selatan 12640. Email : setiarini.mail@gmail.com 
Jurnal Akuntansi \& Perpajakan, Volume 1, No. 2, Januari 2020

\section{PENDAHULUAN}

Usaha Mikro Kecil Menengah (UMKM) di Indonesia dari tahun ke tahun jumlahnya meningkat. Tidak bisa dipungkiri bahwa UMKM memiliki peran yang penting dan strategis dengan jumlah industri yang besar dan terdapat disetiap sektor ekonomi, potensinya yang besar dalam penyerapan tenaga kerja pemberi kontribusi PDB. Data statistika dari Kementrian Koperasi dan Usaha Kecil menunjukkan bahwa jumlah orang yang bekerja di UMKM dari tahun 2012 semakin meningkat dari tahun ke tahun. Saat ini tingkat persaingan amatlah tinggi, sehingga informasi meningkatkan kepekaan konsumen terhadap harga, nilai, pelayanan dan keragaman serta kesegaran produk (Bangsawan Satria, 2015).

Pengalaman di negara-negara maju menunjukkan bahwa UMKM adalah sumber dari inovasi produksi dan teknologi, pertumbuhan wirausaha yang kreatif, dan inovatif, penciptaan tenaga kerja trampil dan fleksibilitas proses produksi untuk menghadapi perubahan permintaan pasar yang semakin beragam segmentasinya dan semakin spesifik. Kemampuan yang dimiliki UMKM tersebut sangat ditentukan oleh sejumlah faktor, diantaranya adalah sumberdaya manusia, penguasaan teknologi, akses ke informasi, pasar output, dan input. Dalam dasawarsa terakhir, perkembangan lingkungan bisnis yang sangat dinamis mempengaruhi setiap perusahaan, baik perusahaan besar menengah, maupun perusahaan kecil. Perubahan teknologi dan variasi produk yang secara cepat adalah dua faktor yang mempengaruhi secara signifikan dari perkembangan bisnis, sehingga seringkali strategi unggulan yang dipilih sebelumnya tidak memadai lagi. Oleh karena itu pemilihan dan penentuan strategi baru diperlukan bagi perusahaan yang lebih kompetitif (Wilantara dan Susilawati, 2016).

UMKM di Indonesia khususnya terdapat beberapa masalah yang harus dihadapi dalam melakukan strategi persaingan dengan pengusaha lain. Strategi menghadapi pasar akan berpengaruh terhadap kegiatan inovasi yang dilakukan perusahaan (Ciptono, 2006; Ellitan, 2006; Gunday et al, 2008). Faktor-faktor keunggulan kompetitif tersebut yang harus dimiliki oleh setiap perusahaan untuk dapat bersaing di pasar dunia adalah : penguasaan teknologi, sumberdaya manusia (pekerja, manajer) dengan kualitas dan 
Jurnal Akuntansi \& Perpajakan, Volume 1, No. 2, Januari 2020

memiliki etos kerja, kreativitas dan motivasi tinggi; tingkat effisiensi dan produktivitas yang tinggi dalam proses produksi; kualitas serta mutu yang baik dari barang yang dihasilkan, sistem manajemen dan struktur organisasi yang baik; tingkat enterpreneurship yang tinggi, yakni seorang pengusaha yang sangat inovatif, kreatif serta memiliki visi yang luas mengenai produk dan lingkungan sekitar usahanya (ekonomi, sosial, politik, dan lain-lain) dan bagaimana cara yang tepat (effektif dan effisien) dalam menghadapi persaing yang ketat dipasar global sehingga dapat mencapai kinerja usaha yang optimum. Menurut Weerawardena et al (2006), strategi inovasi organisasi berpengaruh terhadap kinerja usaha.

Berdasarkan uraian yang dikemukakan di atas agar UMKM dapat unggul dalam kompetititf menghadapi persaingan di era globalisasi, maka diperlukan suatu penelitian analisis faktor orientasi kepemimpinan pasar, strategi inovasi, dan kinerja UMKM (studi kasus UMKM di Jakarta) dengan tujuan ingin mengetahui pengaruh orientasi kepemimpinan pasar terhadap strategi inovasi dan kinerja usaha; pengaruh strategi inovasi terhadap kinerja usaha.

\section{LITERATURE REVIEW}

Orientasi pemimpin pasar adalah strategi mengembangkan pasar secara keseluruhan dengan melindungi dan memperluas pangsa pasar (Tjiptono Fandy, 2008). Ada tiga cara yang dapat digunakan pemimpin pasar untuk memperluas pasar yaitu mencari pemakai baru, mencari kegunaan baru, dan penggunaan yang lebih sering. Untuk mencapai kepemimpinan produk, suatu perusahaan perlu secara terus menerus melakukan pengembangan dan inovasi produk dan jasa yang dihasilkan.

Sedangkan strategi inovasi mencakup konteks tentang keputusan pengembangan produk dibuat dimana beberapa strategi membutuhkan komitmen tinggi untuk untuk inovasi produk dan aktivitas yang lain yang mendukung pencapaian tujuan perusahaan (Abdul, 2015). Proses inovasi pada beberapa perusahaan sering tidak dapat memenuhi tantangan untuk melakukan pengembangan produk baru secara agresif. Hal ini terjadi karena perusahaan-perusahaan tersebut hanya menekankan perhatiannya pada pengembangan yang bersifat jangka pendek tanpa diimbangi pengembangan jangka panjang. Inovasi yang dilakukan 
Jurnal Akuntansi \& Perpajakan, Volume 1, No. 2, Januari 2020

akan dapat menciptakan keunggulan bersaing bagi organisasi perusahaan tersebut dan menciptakan nilai bagi pelanggan (Assauri Sofyan, 2012).

Sementara itu, indikator kinerja usaha bukan hanya dihitung dari laporan keuangan, tetapi penilaian kinerja perusahaan secara subyektif juga digunakan (Powell, 1992; Robinson \& Pearce,1988). Penggunaan penilaian kinerja secara subyektif jelas memiliki beberapa kelebihan dibandingkan indikator kinerja yang dihitung dari laporan keuangan. Kinerja perusahaan didefinisikan sebagai kemampuan perusahaan untuk membuat tindakan dan hasil yang dapat diterima (Pleffer \& Salancik ,1978). Namun kinerja perusahaan harus dapat dikonsepkan dan dioperasionalkan, serta dapat diukur dalam beberapa cara. Alasadi dan Abdelrahim (2007) menyatakan kinerja pada UMKM dapat dilihat dari kepuasan pemilik/manajer atas profit, omset, tahap balik modal dan pengembangan usaha. Menurut Leitner dan Gueldenberg (2006), Oke, et al (2007), Murat dan Baki (2011), indikator pertumbuhan penjualan, pertumbuhan tenaga kerja, dan pertumbuhan pendapatan.
Dari pembahasan di atas, maka dibangun model penelitian dan hipotesis yang dijabarkan sebagai berikut :

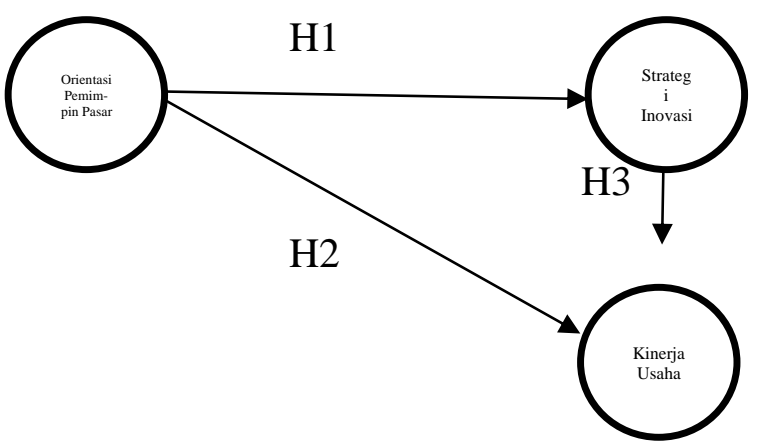

Gambar 1. Model Penelitian

1. H1 : Adanya pengaruh orientasi pemimpin pasar terhadap strategi inovasi

2. H2 : Adanya pengaruh orientasi pemimpin pasar terhadap kinerja usaha 3. H3 : Adanya pengaruh strategi inovasi terhadap kinerja usaha

\section{METODE}

Menurut Sugiyono (2016), metode penelitian pada dasarnya merupakan cara ilmiah untuk mendapatkan data dengan tujuan dan kegunaan tertentu. Data yang digunakan pada penelitian ini adalah data primer dan data sekunder. Variabel yang diamati pada penelitian ini adalah variabel orientasi pemimpin pasar, strategi inovasi, dan kinerja usaha. 
Jurnal Akuntansi \& Perpajakan, Volume 1, No. 2, Januari 2020

Menurut Sugiyono (2016), populasi adalah wilayah generalisasi yang terdiri dari objek atau subjek yang menjadi kuantitas dan karakteristik tertentu yang ditetapkan oleh peneliti untuk dipelajari dan kemudian ditarik kesimpulannya. Populasi penelitian adalah UMKM home industry Jakarta. Responden adalah pemilik atau koordinator atau karyawan yang senior. Tehnik pengumpulan data secara purposive.

Penelitian ini menggunakan alat ukur berupa kuesioner dengan jawaban tertutup sesuai skala Likert 1-5, yaitu 1 = sangat tidak setuju, 2 = tidak setuju, 3 $=$ netral/ragu-ragu, $4=$ setuju, dan $5=$ sangat setuju. Tingkat penilaian responden tentang variabel digunakan rumus rentang skala $(\mathrm{RS})=$ (nilai tertinggi - nilai terendah)/jumlah nilai, sehingga $\mathrm{RS}=(5-1) / 5=0,80$. Kategori tingkat penilaian responden sebagai berikut : sangat rendah $=1,00-1,80$, rendah $=1,81-2,60$, sedang $=2,61-$ 3,40 , tinggi $=3,41-4,20$, sangat tinggi $=4,21-5,00$

Validitas menunjukan derajat ketepatan antara data yang sesungguhnya terjadi pada objek dengan data yang dikumpulkan oleh peneliti untuk mencari validitas sebuah item, kita mengkorelasikan skor item dengan total item-item tersebut (Sugiyono, 2016). Uji validitas ini memastikan bahwa masing-masing pertanyaan akan terklasifikasikan pada variabel-variabel yang telah ditetapkan (construct validity). Apabila suatu pertanyaan mampu mengungkapkan apa yang akan diukur oleh angket tersebut, maka data tersebut disebut valid. Ukuran valid adalah $r$ hitung > r tabel. Sedangkan uji reliabilitas digunakan untuk mengukur apakah jawaban seorang responden konsisten atau stabil dari waktu ke waktu. Apabila responden konsisten dalam menjawab pertanyaan dalam angket, maka data tersebut adalah reliabel. Suatu konstruk atau variabel dikatakan reliabel, jika Cronbach's Alpha $(\alpha)$ dari variabel tersebut memberikan nilai $>0,60$.

Analisa data secara SEM dengan program Lisrel yang dapat menghasilkan uji validitas, reliabilitas, pembentukan model, uji kelayakan model (good of fit), dan uji hipotesis (Ghozali, 2015). Pada uji hipotesis digunakan uji t, apabila t hitung $>1,96$ maka hipotesis alternative akan diterima. Pada penelitian ini juga akan dianalisis pengaruh langsung, tidak langsung, dan total. 
Jurnal Akuntansi \& Perpajakan, Volume 1, No. 2, Januari 2020

\section{HASIL DAN PEMBAHASAN}

Karakteristik responden pada penelitian ini adalah kebanyakan perempuan, berpendidikan rendah, pemilik home industry, dan status usaha perorangan. Sementara itu, variabel yang diamati adalah variabel orientasi kepemimpinan pasar (ORPASAR) yang tercermin pada 5 indikator dan variabel strategi inovasi (INOVASI) yang tercermin pada 9 indikator, dan variabel kinerja usaha (KINERJA) yang tercermin pada 3 indikator. Berdasarkan uji validitas dan reliabilitas, diperoleh bahwa semua indikator adalah valid, karena indikator tersebut memiliki $r$ hitung $>\mathrm{r}$ tabel. Semua variabelnya adalah reliabel, karena semua varabelnya memiliki Cronbach's Alpha $>0,6$.

Tingkat penilaian responden tentang pelaksanaan kegiatan UMKM yaitu variabel orientasi kepemimpinan pasar dan strategi inovasi UMKM adalah tinggi (means variabel tersebut 3,41-4,20), dan variabel kinerja usaha adalah sedang (means variabel tersebut 2,61-3,40). Tingkat penilaian yang tinggi untuk variabel orientasi kepemimpinan pasar tercermin pada 1 indikator utama yaitu perusahaan selalu berupaya mengungguli perusahaan lain yang sejenis dalam hal pengenalan produk baru. Tingkat penilaian yang tinggi untuk variabel strategi inovasi tercermin pada 1 indikator utama yaitu memberikan sistem pelayanan yang baik untuk pelanggan. Sedangkan tingkat penilaian yang sedang untuk variabel variabel kinerja usaha tercermin pada 1 indikator utama yaitu adanya kenaikan 5-10\% pada pendapatan tahun ini dibandingkan dengan tahun lalu.

Dari hasil pengolahan data dengan program Lisrel diperoleh model hubungan antar variabel yang dinyatakan dalam Gambar 1. Dari Gambar tersebut diperoleh model penelitian ini yang dinyatakan dengan 2 persamaan yang menyatakan hubungan antar variabel penelitian ini. Dari persamaan 1 dapat dikatakan bahwa variabel orientasi kepemimpinan pasar mampu menjelaskan variabel strategi inovasi sebesar 4,8\%. Sisanya, 95,2\% mampu dijelaskan oleh variabel lain yang tidak dibahas pada penelitian ini. Dari persamaan 2 dapat dikatakan bahwa variabel orientasi kepemimpinan pasar dan strategi inovasi, menjelaskan variabel kinerja usaha sebesar $62 \%$. Sisanya, 38\% mampu dijelaskan oleh 
Jurnal Akuntansi \& Perpajakan, Volume 1, No. 2, Januari 2020

variabel lain yang tidak dijelaskan pada penelitian ini.

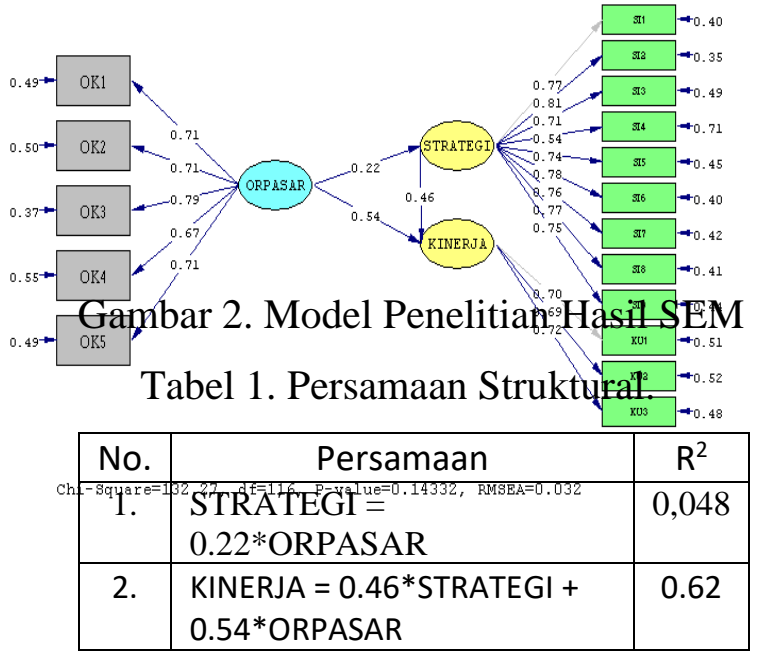

Berdasarkan tabel 2 tentang uji good of fit (GoF), maka diperoleh nilainilai sebagai berikut ECVI = 1.48 (baik), AIC $=206.27$ (baik), CAIC $=352.1$ (baik), NFI $=0.95$ (baik), PNFI $=0.81$ (baik), RFI = 0.94 (baik), RMR $=0.037$ (baik), $\mathrm{AGFI}=0.87$ (baik), $\mathrm{PGFI}=0.68$ (baik). Nilai tersebut menunjukkan adanya kecocokan model.

Tabel 2. Goodness of Fit

\section{Statistics (GoF)}

\begin{tabular}{|c|l|c|c|}
\hline No & $\begin{array}{l}\text { Goodness of } \\
\text { Fit Statistics }\end{array}$ & Standard & $\begin{array}{c}\text { Keterang } \\
\text { an }\end{array}$ \\
\hline 1. & Minimum & $132.27(\mathrm{P}$ & Not \\
& Fit Function & $=0.14)$ & Good \\
& $\begin{array}{l}\text { Chi-Square } \\
=133.54(\mathrm{P}\end{array}$ & & \\
& $=0.13)$ & & \\
\hline
\end{tabular}

\begin{tabular}{|c|c|c|c|}
\hline 2. & $\begin{array}{l}\text { Estimated } \\
\text { Non- } \\
\text { centrality } \\
\text { Parameter } \\
(\mathrm{NCP})= \\
16.27\end{array}$ & $\begin{array}{c}(0.0 ; \\
48.82)\end{array}$ & Marginal \\
\hline 3. & $\begin{array}{l}\text { Population } \\
\text { Discrepancy } \\
\text { Function } \\
\text { Value (F0) } \\
=0.12\end{array}$ & $(0.0 ; 0.35)$ & Marginal \\
\hline 4. & $\begin{array}{l}\text { Root Mean } \\
\text { Square Error } \\
\text { of } \\
\text { Approximati } \\
\text { on } \\
(\text { RMSEA) = } \\
0.032\end{array}$ & $\begin{array}{l}(0.0 ; \\
0.055)\end{array}$ & Marginal \\
\hline 5. & $\begin{array}{l}\text { Expected } \\
\text { Cross- } \\
\text { Validation } \\
\text { Index } \\
(\mathrm{ECVI})= \\
1.48 \\
\end{array}$ & $\begin{array}{l}\text { Saturated } \\
\text { Model = } \\
2.20 . \\
\text { Independen } \\
\text {-ce Model } \\
=19.69 \\
\end{array}$ & Good \\
\hline 6. & $\begin{array}{l}\text { Model AIC } \\
=206.27\end{array}$ & $\begin{array}{l}\text { Independen } \\
\text { ce AIC = } \\
2736.78 \\
\text { Saturated } \\
\text { AIC = } \\
306.00 \\
\end{array}$ & Good \\
\hline 7. & $\begin{array}{l}\text { Model } \\
\text { CAIC = } \\
352.11\end{array}$ & $\begin{array}{l}\text { Independen } \\
\text { ce CAIC = } \\
2803.79 \\
\text { Saturated } \\
\text { CAIC = } \\
909.07\end{array}$ & Good \\
\hline 8. & $\begin{array}{l}\text { Normed Fit } \\
\text { Index (NFI) } \\
=0.95\end{array}$ & $\begin{array}{l}\text { Non- } \\
\text { Normed Fit } \\
\text { Index } \\
(\mathrm{NNFI})= \\
0.99 \\
\end{array}$ & Good \\
\hline 9. & $\begin{array}{l}\text { Parsimony } \\
\text { Normed Fit } \\
\text { Index } \\
(\text { PNFI) = } \\
0.81\end{array}$ & $\begin{array}{l}\text { Non- } \\
\text { Normed Fit } \\
\text { Index } \\
(\mathrm{NNFI})= \\
0.99\end{array}$ & Good \\
\hline 10 & $\begin{array}{l}\text { Comparativ } \\
\text { e Fit Index } \\
(\mathrm{CFI})=0.99\end{array}$ & $\begin{array}{l}\text { Non- } \\
\text { Normed Fit } \\
\text { Index } \\
(\mathrm{NNFI})= \\
0.99 \\
\end{array}$ & Marginal \\
\hline 11 & $\begin{array}{l}\text { Incremental } \\
\text { Fit Index } \\
(\text { IFI })=0.99\end{array}$ & $\begin{array}{l}\text { Non- } \\
\text { Normed Fit } \\
\text { Index } \\
(\mathrm{NNFI})= \\
0.99\end{array}$ & Marginal \\
\hline
\end{tabular}


Jurnal Akuntansi \& Perpajakan, Volume 1, No. 2, Januari 2020

\begin{tabular}{|c|c|c|c|}
\hline 12 & $\begin{array}{l}\text { Relative Fit } \\
\text { Index (RFI) } \\
=0.94\end{array}$ & $\begin{array}{l}\text { Non- } \\
\text { Normed Fit } \\
\text { Index } \\
(\mathrm{NNFI})= \\
0.99\end{array}$ & Good \\
\hline 13 & $\begin{array}{l}\text { Root Mean } \\
\text { Square } \\
\text { Residual } \\
(\text { RMR })= \\
0.037\end{array}$ & 0.049 & Good \\
\hline 14 & $\begin{array}{l}\text { Adjusted } \\
\text { Goodness of } \\
\text { Fit Index } \\
(\text { AGFI) }= \\
0.87\end{array}$ & $\begin{array}{l}\text { Goodness } \\
\text { of Fit } \\
\text { Index } \\
(\mathrm{GFI})= \\
0.90\end{array}$ & Good \\
\hline 15 & $\begin{array}{l}\text { Parsimony } \\
\text { Goodness of } \\
\text { Fit Index } \\
(\mathrm{PGFI})= \\
0.68\end{array}$ & $\begin{array}{l}\text { Goodness } \\
\text { of Fit } \\
\text { Index } \\
(\mathrm{GFI})= \\
0.90\end{array}$ & Good \\
\hline
\end{tabular}

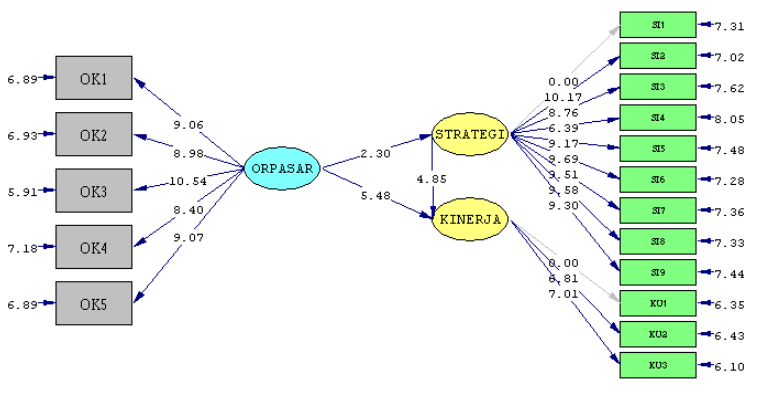

Chi-square $=132.27, d f=116, \quad P-v a l u e=0.14332$, RMgEA $=0.032$

Gambar.2. Uji T

Berdasarkan uji $\mathrm{T}$ yang dijabarkan pada Gambar 2, maka dapat diperoleh informasi bahwa $\mathrm{H} 1$ diterima karena $t$ hitung dari hipotesis tersebut $\geq$ 1,976. Hal ini menunjukkan bahwa orientasi kepemimpinan pasar berpengaruh terhadap strategi inovasi. Keragaman nilai pada dua variabel tersebut mampu menjelaskan hubungan antar nilai tersebut. Hal ini sesuai dengan hasil penelitian Abdul (2015), bahwa orientasi kepemimpinan pasar berpengaruh terhadap strategi inovasi.

$\mathrm{H} 2$ diterima karena t hitung dari hipotesis tersebut $\geq 1,976$. Hal ini menunjukkan bahwa orientasi kepemimpinan pasar berpengaruh terhadap kinerja usaha. Keragaman nilai pada dua variabel tersebut mampu menjelaskan hubungan antar nilai tersebut. Hal ini tidak sesuai dengan hasil penelitian Abdul (2015) bahwa orientasi kepemimpinan pasar tidak berpengaruh terhadap kinerja usaha.

H3 diterima karena t hitung dari hipotesis tersebut $\geq 1,976$. Hal ini menunjukkan bahwa strategi inovasi berpengaruh terhadap kinerja usaha. Keragaman nilai pada dua variabel tersebut mampu menjelaskan hubungan antar nilai tersebut. Hal ini sesuai dengan hasil penelitian Murat Atalay et al (2013) dan Abdul (2015) bahwa strategi inovasi berpengaruh terhadap kinerja usaha.

Dari Gambar 1, dapat diketahui juga pengaruh langsung, tidak langsung dan total. Ada 1 jalur yang dihasilkan penelitian ini yaitu jalur orientasi kepemimpinan pasar-strategi inovasikinerja usaha. Variabel strategi inovasi dapat berfungsi sebagai variabel 
Jurnal Akuntansi \& Perpajakan, Volume 1, No. 2, Januari 2020

intervening, yaitu variabel pendukung bagi variabel orientasi kepemimpinan pasar dalam usaha meningkatkan kinerja usaha. Lihat Tabel 3.

Tabel 3. Pengaruh

Langsung, Tidak Langsung, Total

\begin{tabular}{|c|c|c|c|c|c|}
\hline No & Jalur & Variabe & \multicolumn{3}{|c|}{ Pengaruh } \\
\cline { 4 - 6 } & $\begin{array}{c}\text { Langsun } \\
\text { I antara }\end{array}$ & & $\begin{array}{c}\text { Langsun } \\
\mathrm{g}\end{array}$ & $\begin{array}{c}\text { Tidak } \\
\text { Langsung }\end{array}$ & Total \\
\hline 1. & $\begin{array}{l}\text { Orpasar } \\
\text { Kinerja }\end{array}$ & Inovasi & 0.54 & 0.101 & 0.64 \\
& & & $0.22^{*} 0.46$ & 1 \\
\hline
\end{tabular}

Implikasi penelitian ini adalah kinerja usaha UKM bidang usaha home industry di Jakarta masih perlu ditingkatkan. Meningkatnya kinerja usaha tercermin dari adanya kenaikan 5$10 \%$ pada pendapatan tahun ini dibandingkan dengan tahun lalu. Apabila suatu usaha ingin melakukan kegiatan peningkatan kinerja usaha maka operasional usaha tersebut berdasarkan orientasi kepemimpinan pasar berupa perusahaan selalu berupaya mengungguli perusahaan lain yang sejenis dalam hal pengenalan produk baru. Kegiatan tersebut dapat memicu peningkatan kegiatan inovasi yang tercermin dari adanya sistem pelayanan yang baik untuk pelanggan.

\section{KESIMPULAN}

Tingkat pencapaian kinerja usaha dari UKM di Jakarta, masih perlu ditingkatkan. Faktor penentunya antara lain orientasi kepemimpinan pasar, dan strategi inovasi. Hal tersebut dikarenakan adanya pengaruh orientasi kepemimpinan pasar dan strategi inovasi secara parsial terhadap kinerja usaha, serta variabel strategi inovasi dapat berfungsi sebagai faktor pendukung bagi variabel orientasi kepemimpinan pasar dalam meningkatkan kinerja usaha UMKM.

Diperlukan variabel penentu peningkatan kinerja usaha lainnya sehingga variabel-variabel yang diamati dapat lebih besar menjelaskan variabel kinerja usaha antara lain investasi, dukungan pemerintah dan pihak-pihak yang mempunyai kepentingan terhadap UMKM.

Bimbingan terhadap pelaku UMKM antara lain harus berani berinovasi dan menjalankan usaha dengan berorientasi pada pemimpin pasar. Kegiatan tersebut dapat terinspirasi melalui kegiatan penambahan wawasan melalui pelatihan, studi banding, temu bisnis, dan kegitan peningkatan motivasi untuk maju melalui kegiatan UKM yang 
Jurnal Akuntansi \& Perpajakan, Volume 1, No. 2, Januari 2020

ditekuni saat ini, serta pelatihanpelatihan strategi bisnis.

\section{Daftar Pustaka}

Abdul Haris Perwiranegara. 2015. Pengaruh Orientasi Kepemimpinan Pasar dan Strategi Inovasi Terhadap Kinerja UKM (Studi pada UKM Kerajinan Bubut Kayu Kota Blitar). Jurnal Aplikasi Manajemen (JAM), Vol 13, No $1 ; 77-89$.

Alasadi, R\& Abdelrahim, A. 2007. Critical Analysis And Modeling Of Small Business Performance (Case Stydy: Syira). Journal of Asia Enterpreunership and Sustainability, Volume III, Issue 2.

Assauri, Sofyan. 2012. Strategi

Marketing Sustaining lifetime.

Jakarta : Raja Grafindo Persada.

Bangsawan Satria, 2015 Pemasaran

Usaha Kecil; Kasus Industri

Pengolahan Makanan.

Yogyakarta : Graha Ilmu.

Badan Pusat Statistik. 2012. Statisitik Indonesia 2012 Jakarta : Badan Pusat Statitstik.

Ciptono. W. S, (2006), A Sequential Model Of Innovation StrategyCompany Non-Financial Performance Links, Gajah Mada International journal of Bussiness, 82; 137-178

Ellitan, L. 2006. Strategi Inovasi dan Kinerja Perusahaan Manufaktur Di Indonesia: Pendekatan Model Simultan dan Model Sekuensial. Jurnal Manajemen, 6(11); 1-22.

Ghozali, Imam. 2016. Aplikasi Analisa Multivariate Dengan Program IBM SPSS23. Semarang: BPFE Universitas Diponegoro.
Gunday, G., Ulusoy, G., Kilic, K., Alpkan, L. 2008. Effect of Innovation Types on Firm Performance. Free Research; 143.

Indriati, Nurul, dan Langenberg, Maria. 2004. Factors Affecing Business Success among SME's Empirical Evidences from Indonesia

Leitner, K., dan Gueldenberg, S. 2006. Generic Strategies and Firm Performance: A Longitudinal Study of Austrian SMEs, Prosiding submission to the Annual Conference on Corporate Strategy; 1-34.

Murat, I.A., dan Baki, B. 2011. Antecedents and Performance Impacts of Product Versus Process Innovation Empirical Evidence From SMEs Located in Turkish Science and Technology Parks. European Journal of Innovation Management, 14 (2); 172-206.

Murat Atalay, Nilgun Anafarta, Fulya Sarvan. 2013. The Relationship Between Innovation and Firm Performance : An Empirical Evidence From Turkish Automotive Supplier Industry. Procedia-Social and Behavioral Sciences 75; 226-236.

Oke, A., Burke, G., and Myers, A. 2007. Innovation types and innovation management practicesin service companies. International Journal of Operations \& Production Management, 27 (6); 564-587.

Pfeffer, J \& G. Salanick.1978. The External Control of Organizations: a resource dependence perspective. New York Harper \& Row. 
Jurnal Akuntansi \& Perpajakan, Volume 1, No. 2, Januari 2020

Powell, T. 1992. Organizatioal Alignment as Competive Advantage. Strategic Management Journal 13 (2); 119 $-134$.

Robinson, R Jr \& J.Pearce. 1988.

Planned Patterns of Stategic Behavior and Their Relationship to Business Unit Performance Strategic Management Journal9(1); 43- 60 .

Tjiptono, Fandy. 2008. Strategi Pemasaran. Yogyakarta : Andi.
Weerawardena, J., O'Cass, A., and Julian, C. 2006. Does Industry Matter? Examining the Role of Industry Structure and Organizational Learning In Innovation and Brand Performance. Journal of Business Research 59; 37-45.

Wilantara, Rio F dan Susilawati. 2016. Strategi \& Kebijakan Pengembangan UMKM. Upaya Meningkatkan Daya Saing UMKM Nasional di Era MEA. Bandung : Refika Aditama. 